\title{
PRETREATMENT OF LIGNOCELLULOSIC BIOMASS FOR ENZYMATIC HYDROLYSIS
}

\author{
Doan Thai Hoa \\ Hanoi University of Technology, Vietnam \\ Tran Dinh Man \\ Institute of Biotechnology, VAST \\ Ngo Viet Hau \\ Pulp and Paper Corporation, Vietnam \\ Received 07 December 2007
}

\begin{abstract}
The cost of raw materials continues to be a limiting factor in the production of bio-ethanol from traditional raw materials, such as sugar and starch. At the same time, there are large amount of agricultural residues as well as industrial wastes that are of low or negative value (due to costs of current effluent disposal methods). Dilute sulfuric acid pretreatment of elephant grass and wood residues for the enzymatic hydrolysis of cellulose has been investigated in this study.

Elephant grass (agricultural residue) and sawdust (Pulp and Paper Industry waste) with a small particulate size were treated using different dilute sulfuric acid concentrations at a temperature of $140-170^{\circ} \mathrm{C}$ within $0.5-3$ hours. The appropriate pretreatment conditions give the highest yield of soluble saccharides and total reducing sugars.
\end{abstract}

\section{INTRODUCTION}

In Vietnam as in many other countries, ethanol is the most alternative to gasoline. Neat ethanol production in Vietnam is about 76.63 million liter/year. A haft of its amount is used for wine and liquor production; $15-20 \%$ serves the industrial and medical purposes; around $10 \%$ of amount of ethanol is used as fuel alcohol.

The target of Vietnamese government is to produce 500 million liters of bio-ethanol fuel by 2020 (to blend 5 billion liters of gasohol E10). Agricultural residues, bagasses, elephant grass, woody wastes... can be used as the feedstocks for bio-ethanol production.

Currently practical technologies of ethanol production in Vietnam are based on the fermentation of sugars from starch and molasses. The production of renewable fuels from biomass is a great of interest. Many phisio-chemical structural and compositional factors hinder the enzymatic digestibility of cellulose present in lignocellulosic biomass. The goal of any pretreatment is to alter or remove structural and compositional impediments to hydrolysis in order to improve the rate of enzymatic hydrolysis and increase yields of fermentable sugars from cellulose or hemicellulose. 


\section{MATERIAL AND METHODS}

\subsection{Sample preparation}

The waste sawdust from acacia (wood residues) with average size of 2-5 $\mathrm{mm}$ was obtained locally. The dried trunk of elephant grass - Pennisetum purpureum was cut by Retsch mill using the screen with the mesh of $1.5 \mathrm{~mm}$.

\subsection{Analytical methods}

TAPPI testing methods were used for determinations of wood contents such as moisture (T 210 cm-93), ash (T 211 om-93), solvent extractives (T $204 \mathrm{~cm}-97$ ), water solubility (T $207 \mathrm{~cm}-99$ ), lignin (T $222 \mathrm{om}-98$ ), cellulose (T $17 \mathrm{wd}-70$ ), and pentosans (T $223 \mathrm{~cm}-84$ ).

Analysis of total reducing sugars was performed according to the Bectran with the use of Fehling solutions $\mathrm{A}\left(\mathrm{CuSO}_{4}\right)$ and B (potasium-sodium tartarate) in alkaline medium.

\subsection{Pretreatment of samples}

Samples were pretreated with hot water and mineral acids. The slurry was dewatered, washed thoroughly and subjected to dry mass content determination. The filtrate and washes were collected for analysis of total reducing sugars. The monomeric sugars were analyzed using highperformance liquid chromatography (HPLC).

\section{RESULTS AND DISCUSSION}

Processing of lignocellulosics to ethanol consists of four major unit operation, such as pretreatment, hydrolysis, fermentation, and product separation. Pretreatment is an important tool for practical cellulose conversion processes. An effective pretreatment is characterized by several criteria. Pretreatment methods are either physical or chemical. Physical pretreatment methods include mechanical reduction in biomass particulate size, steam explosion, and hydrothermolysis. The most commonly used mineral acids and bases are $\mathrm{H}_{2} \mathrm{SO}_{4}$ and $\mathrm{H}_{3} \mathrm{PO}_{4}$.

\subsection{Chemical composition of the elephant grass and wood residues}

Lignocellulosic materials consist of cellulose, hemicellulose, lignin, extractives and inorganics. The chemical composition affects the sugars yield in enzymatic hydrolysis of lignocellulosic biomass.

Table 1: The chemical composition of biomass, wt\% of oven dry basis.

\begin{tabular}{clcc}
\hline No. & Chemical components & Elephant Grass & Wood residues \\
\hline 1 & Ash & 5.3 & 2.3 \\
2 & Extractives in Ethanol-Benzene & 7.0 & 3.0 \\
3 & Extractives in hot water & 18.2 & 3.7 \\
4 & Extractives in cold water & 17.2 & 2.5 \\
5 & Cellulose & 43.3 & 40.6 \\
6 & Carbohydrates & 66.3 & 63.8 \\
7 & Pentosans & 19.5 & 20.1 \\
8 & Acid-insoluble Lignin & 17.3 & 22.7 \\
\hline
\end{tabular}


Elephant grass (Figure 1) is one of the highest yielding tropical forage grasses. The chemical analyses of elephant grass and sawdust are shown in table 1 .

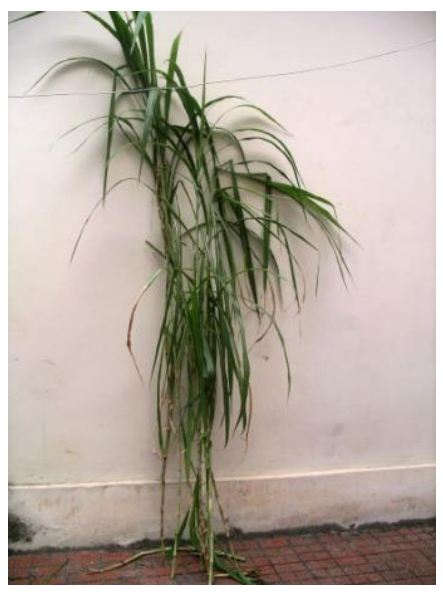

a

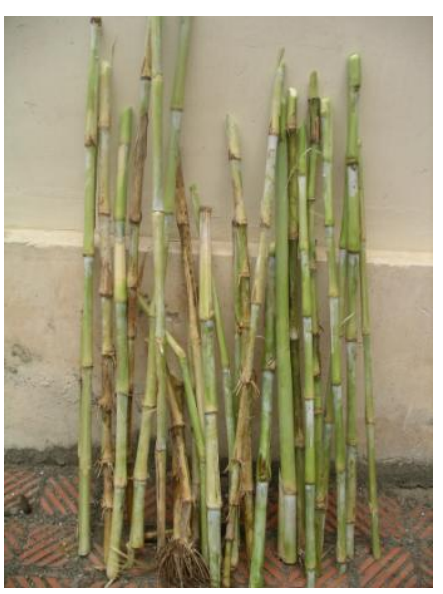

b

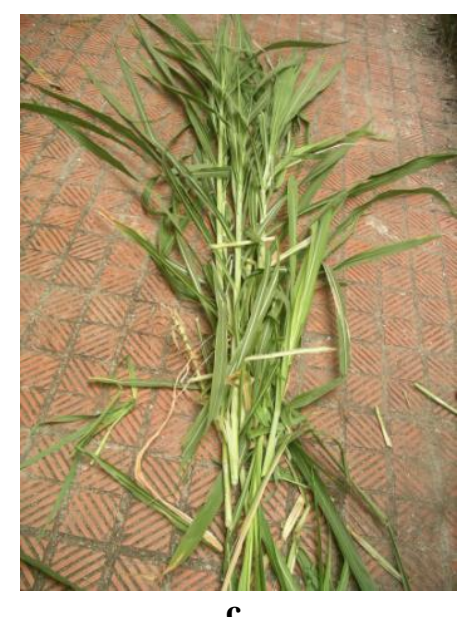

Fig. 1: Elephant grass (a); Tree - trunk (b); Leaf (c).

Elephant grass contains more hemicellulose, which gives high extractives content in cold and hot water compared to wood residues. It was reported that elephant grass hay contained $68,6 \%$ of total carbohydrate (Jame A. Duke, 1983).

\subsection{Acid pretreatment}

Dilute sulfuric acid hydrolysis is a favorable pretreatment before enzymatic hydrolysis. It is usually set at a temperature between $140 \div 170^{\circ} \mathrm{C}$ in one stage or a high temperature $(180 \div$ $240^{\circ} \mathrm{C}$ ) with a short residence time [2].

Acid pretreatment conditions of elephant grass and sawdust residue were studied. The effect of treatment temperature on overall hydrolysis yield and reducing sugars yield were shown in table 2 .

Table 2: Effects of pretreatment temperature on saccharification (Treated: time $0.5 \mathrm{~h}$; solid:liquid ratio $=1: 10$ ).

\begin{tabular}{|c|c|c|c|c|c|}
\hline \multirow{2}{*}{$\begin{array}{c}\text { Temperature } \\
\left({ }^{\circ} \mathrm{C}\right)\end{array}$} & \multirow{2}{*}{$\begin{array}{c}\text { Acid } \\
\text { loading } \\
\text { (wt\%) }\end{array}$} & \multicolumn{2}{|c|}{ Soluble saccharides, wt $\%$} & \multicolumn{2}{|c|}{ Reducing sugars, wt \% } \\
\hline & & $\begin{array}{c}\text { Elephant } \\
\text { grass }\end{array}$ & $\begin{array}{l}\text { Wood } \\
\text { residues }\end{array}$ & $\begin{array}{c}\text { Elephant } \\
\text { grass }\end{array}$ & $\begin{array}{l}\text { Wood } \\
\text { residues }\end{array}$ \\
\hline 145 & 0 & 22.5 & 10.2 & 7.0 & 1.2 \\
\hline 145 & 0.5 & 27.5 & - & 7.8 & - \\
\hline 145 & 1.0 & - & 15.6 & - & 4.3 \\
\hline 155 & 0 & 23.3 & 12.5 & 7.2 & 1.5 \\
\hline 155 & 0.5 & 29.3 & - & 8.6 & - \\
\hline 155 & 1.0 & - & 17.2 & - & 6.7 \\
\hline 165 & 0 & 26.7 & 13.8 & 7.9 & 3.2 \\
\hline 165 & 0.5 & 30.3 & - & 9.8 & - \\
\hline 165 & 1.0 & - & 22.5 & - & 12.4 \\
\hline
\end{tabular}


Tables 1 and 2 showed that almost hemicellulose and a small part of cellulose were removed at temperature of $165^{\circ} \mathrm{C}$. The amount of total reducing sugars in prehydrolysates were much lower than that of soluble sacchrides at the same pretreatment conditions

Table 3: Effects of pretreatment time on saccharification (H2SO4 loading $0.5 \%$ for grass and $1 \%$ for sawdust; Temp. $165^{\circ} \mathrm{C}$; solid:liquid ratio= 1:10).

\begin{tabular}{ccccc}
\hline \multirow{2}{*}{$\begin{array}{c}\text { Treatment } \\
\text { time (h) }\end{array}$} & \multicolumn{2}{c}{ Soluble saccharides, wt $\%$} & \multicolumn{2}{c}{ Reducing sugars, wt \% } \\
\cline { 2 - 5 } & Elephant grass & Wood residues & Elephant grass & Wood residues \\
\hline 0.5 & 30.6 & 22.1 & 9.8 & 12.2 \\
1.0 & 37.9 & 23.0 & 15.2 & 13.3 \\
1.5 & 40.3 & 23.2 & 15.4 & 12.7 \\
2.0 & 41.7 & 23.6 & 14.8 & 11.2 \\
2.5 & 42.1 & 23.9 & 14.2 & 11.0 \\
3.0 & 42.3 & 24.8 & 13.7 & 10.1 \\
\hline
\end{tabular}

The treatment time did not significantly influence the release of saccharides. Increasing treatment time was lead to form by-products of acid hydrolysis. The most by-products are furans, carboxylic acids and phenolic compound (Palmqvist, 1998). Furfural and 5hydroxymethyl furfural are formed by decomposition of pentoses and hexoses, respectively. Formic and acetic acids may be formed from metoxy and acetyl groups in the hemicellulose... The concentration of these by-products in hydrolyzates depends on raw lignocellulosic materials. Therefore, reasonable treatment time for both elephant grass and sawdust might be 1.0 - 1.5 hours.

Table 4: Effects of sulfuric acid loading on saccharification (Treated conditions: time 3 hrs; temperature $165^{\circ} \mathrm{C}$; solid:liquid $=1: 10$ ).

\begin{tabular}{ccccc}
\hline \multirow{2}{*}{$\begin{array}{c}\text { Acid loading } \\
(\mathbf{w t} \%)\end{array}$} & \multicolumn{2}{c}{ Soluble saccharides, wt $\%$} & \multicolumn{2}{c}{ Reducing sugars, wt \% } \\
\cline { 2 - 5 } & Elephant grass & Wood residues & Elephant grass & Wood residues \\
\hline 0 & 37.6 & 17.2 & 9.5 & 5.5 \\
0.5 & 38.9 & - & 14.1 & - \\
0.8 & 39.9 & - & 14.9 & - \\
1.0 & 41.6 & 24.8 & 15.2 & 10.4 \\
2.0 & 41.8 & 25.2 & 15.5 & 10.7 \\
3.0 & 42.8 & 28.0 & 18.0 & 13.5 \\
4.0 & - & 28.8 & - & 14.2 \\
5.0 & 43.2 & 29.3 & 18.9 & 14.9 \\
\hline
\end{tabular}

As acid loads increased, the amount of reducing sugars increased very little. This may cause by the degradation of sugars at high acid concentration. In these treatment conditions, a part of cellulose was released. 
High-performance liquid chromatography (HPLC) was used to analyze the composition of the hydrolyzates. The HPLC system was Shimadzu - Japan with detectors DAD and RF. The C18 $4.6 \mathrm{~mm} \times 5 \mu \mathrm{m}$ column was used in all analyses. Solvent system was acetonitrile:water (75:25); the flow rate was set at $2 \mathrm{ml} / \mathrm{min}$. The results of HPLC analyses on elephant grass and acacia sawdust with dilute sulfuric acid were present in figure 2 and 3.

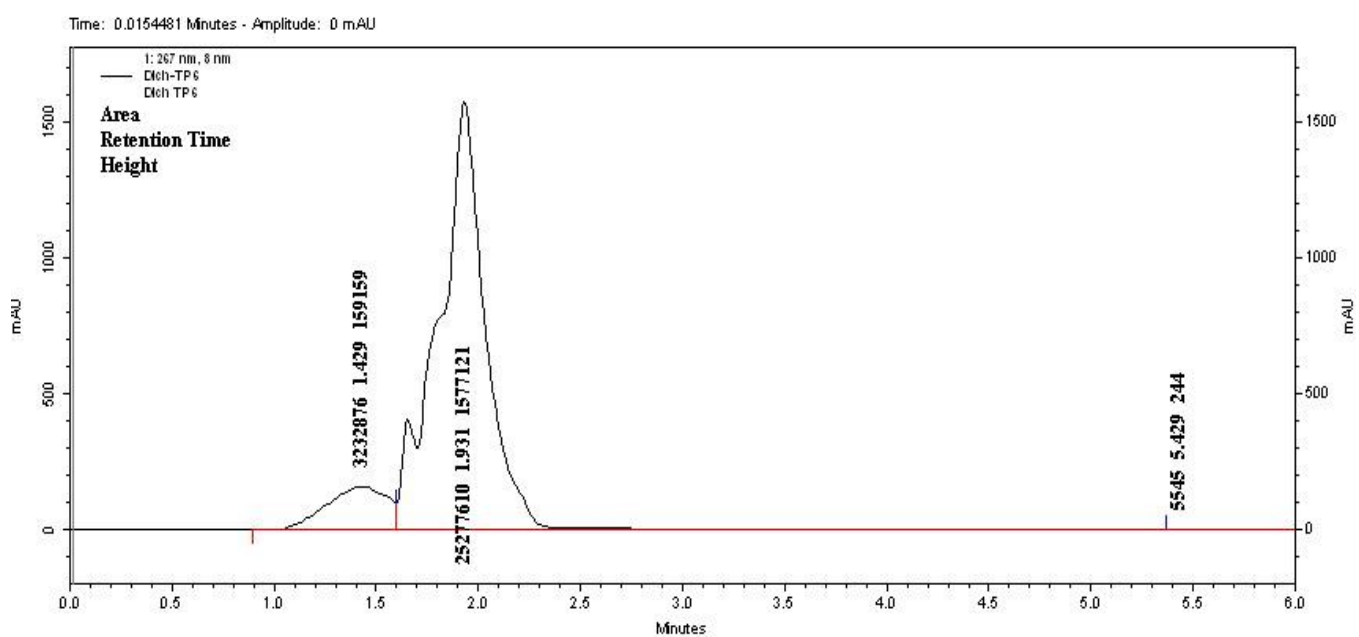

Fig. 2: Elephant grass pretreated with dilute sulfuric acid: (acid loading $0.5 \mathrm{wt} \%$; temperature $165^{\circ} \mathrm{C}$; time $1 \mathrm{hr}$; solid:liquid $=1: 10$ ).

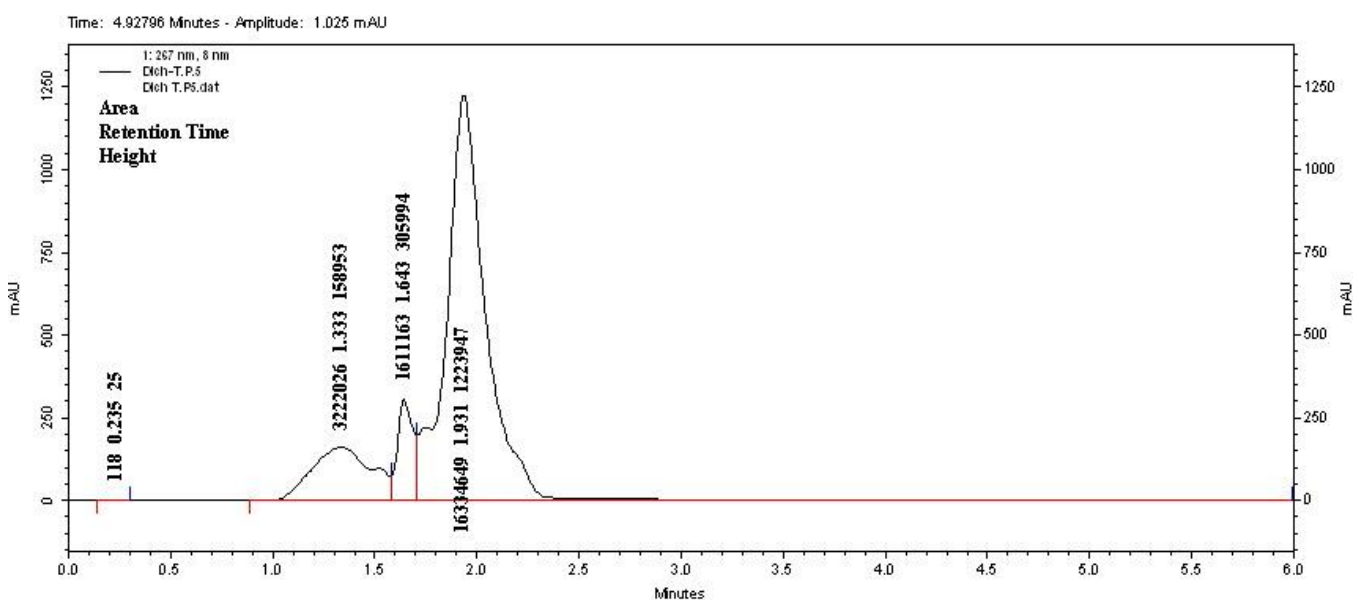

Fig. 3: Acacia sawdust pretreated with dilute sulfuric acid (acid loading $1.0 \mathrm{wt} \%$; temperature $165^{\circ} \mathrm{C}$; time $1 \mathrm{hr}$; solid:liquid = 1:10).

\section{CONCLUSION}

Dilute sulfuric acid pretreatment is effective for the solubilization of hemicellulose. During the pretreatment steps, the struture and composition is modified in order to make cellulose more amenable to enzymatic hydrolysis. The optimal conditions for acid pretreatment are acid loading $0.5 \div 1.0 \mathrm{wt} \%$ (\% kg of $\mathrm{H}_{2} \mathrm{SO}_{4} \mathrm{vs}$. $\mathrm{kg}$ of dry biomass); treatment temperature $165^{\circ} \mathrm{C}$; treatment time 1 hour; and solid to liquid ratio is 1 to 10 . 


\section{ACKNOWLEDGEMENT}

This study was supported by the Governmental Program for Natural Sciences NCCB 5.025.06. Authors would like to thank Sao Do International Co. Ltd. for providing the elephant grass.

\section{REFERENCES}

1. Jame A. Duke, (1983), Handbook of Energy Crops.

2. Lee, J. (1997), Biological conversion of lignocellulosic biomass to ethanol, J. Biotechnol. $56,1-24$

3. Palmqvist, E. (1998), Fermentation of lignocellulosic hydrolyzates: inhibition and detoxification, Ph. D thesis, Lund Univ., Sweden.

4. Baugh, K.D., Levy, J.A., and McCarty, P.L. (1988), Thermomechanical pretreatment of lignocellulose to enhance methane fermentation: II. Evaluation and application of pretreatment model. Biotechnol. and Bioeng. 31, 62-70.

5. Jarvis, E.E. (2005), Biomass Refining: The Future of Ethanol, National Bioenergy Center, National Renewable Energy Laboratory, Golden, Colorado - IREE Symposium, November 29.

6. Lindstedt, J. (2003), Alcohol Production from Lignocellulosic Feedstock, BioAlcohol Foundation Sweden, 228-237.

7. Mosier, N., Wyman, C., Dale, B., Elander, R., Lee, Y.Y., Holtzapple, M., and Ladish, M. (2005), Feature of Promising Technologies for Pretreatment of Lignocellulosic Biomass, Bioresource Technol. 96 (2005), 673-686.

8. Vedernikov, N. (1999), New Technology for Furfural and Bioethanol Production from Low Quality Foliage Wood, 10th International Symposium on Wood and Pulping Chemistry, Yokohama, Japan, 1-10 June 1999. 